\title{
Research on the Relationship between Tourism and Economic Growth under the Construction of Silk Road Economic Belt
}

\author{
Wang Qi \\ International Business School, \\ Shaanxi Normal University, \\ Xi'an 710062, \\ E-mail: $1239765205 @ q q . c o m$
}

\author{
Yao $\mathrm{Yu}$ \\ International Business School, \\ Shaanxi Normal University, \\ Xi'an 710062 \\ E-mail: $1301424812 @ q q . c o m$
}

\begin{abstract}
Neoclassical economics believes that the market force has its effectiveness and the market is the main means of resource allocation, and microeconomics believes that complete information is the premise of realizing the optimal allocation of resources. Therefore, in order to maximize the economic efficiency, the market must give full play to the role of "invisible hand". Shaanxi, as the outset of the Silk Road, has a long cultural history, so it is more meaningful to study the relationship between tourism and dynamic economic growth in Shaanxi Province.
\end{abstract}

Keywords-Tourism industry; Economic Growth; Silk Road Economic Belt

\section{INTRODUCTION}

In 1899, Bodio L. Bodiowas the first to study the economy of tourism, opening the way for scholars from all over the world to study the economic effects of modern tourism. Mathieson and Wall apply the multiplier effect theory to the tourism industry and believe that tourism consumption can promote a double increase in national income. Archer (1985) further develops the theory of tourism multiplier, and points out that tourism multiplier is the ratio of the change of tourism consumption with direct effect, indirect effect and inductive effect to the initial direct change in the economic system. Will adjust the whole pattern of tourism industry and eventually promote the development of a country's economy [1]. Dritsakis (2004) collected data on Greek tourism income and gross national product (GNP) over the past 40 years. Using the Granger causality test, Dritsakis pointed out that there is a strong Granger causality relationship between Greek economic growth and tourism income. Economic growth and tourism development are mutually reinforcing [2]. Balaguer and Jorda set up an economic model by using relevant variables such as real GDP and real international tourism income from 1975 to 1997, and concluded that tourism has a pulling effect on the economic growth of Spain, and the hypothesis supports the assumption that tourism - driven economic growth is supported [3] Qu Hua and Xia Jiechang (2011) using vector autoregressive model to study the relationship between tourism development and economic growth in China, it is concluded that there is a long-term equilibrium and stability relationship between tourism and economic growth in China, and there is economic growth to domestic tourism. One-way causality between International Tourism and domestic Tourism [4] Li Qiuyu (2015) analyzed the relationship between tourism dependence and economic growth in Guangdong Province from different spatial scales, and found that the relationship between them presented inverted U-shaped curve and fixed effect model was used to analyze the causes of the relationship. It is found that when the dependence on tourism reaches a certain degree, tourism exerts an inhibitory effect on the manufacturing industry, leading to "Dutch disease effect". [5]

\section{MODEL CONSTRUCTION}

\section{A. Cointegration}

Integral theory is an econometric analysis method, which is mainly used to study the long-term equilibrium relationship between non-stationary economic variables. If two or more variables are single-integer variables and the number of single-integer variables is the same, when their linear combination is zero-order single-integer sequence, these variables satisfy cointegration. The definition of cointegration can be expressed as: If the sequence $X 1 \mathrm{t}, \mathrm{X} 2 \mathrm{t}, \ldots, \mathrm{X} \mathrm{kt}$ is all $\mathrm{d}$-ordered, if there is a vector $\alpha=[\alpha 1, \alpha 2, \ldots, \alpha \mathrm{k}]$, let $\mathrm{Zt}=\alpha$ $\mathrm{Xt} \sim \mathrm{I}(\mathrm{d}-\mathrm{b})$, where $\mathrm{b}>0, \mathrm{Xt}=[\mathrm{X} 1 \mathrm{t}, \mathrm{X} 2 \mathrm{t}, \ldots, \mathrm{X} \mathrm{kt}] \mathrm{T}$, then the sequence $X 1 t, X 2 t, \ldots, X k t$ is considered to be $(\mathrm{d}, \mathrm{b})$ order cointegration, denoted as $\mathrm{X} \mathrm{t} \sim \mathrm{CI}(\mathrm{d}, \mathrm{b}), \alpha$ is a cointegration vector.

\section{B. Error Correction Model}

Error correction model is a special form of difference equation that reflects the effect of long term equilibrium fluctuation on short term fluctuation. It is composed of disequilibrium error, nutrient variable of original variable and random error term. If $\mathrm{X}$ and $\mathrm{Y}$ are all first-order single integer variables and there is a cointegration relationship, the simplest error correction model expression is: $\Delta \mathrm{Yt}=\beta 0 \Delta \mathrm{Xt}+\beta 1 \mathrm{ECM} \mathrm{t}$ $-1+\mathrm{u}$ t. $(\beta 1 \mathrm{ECM} \mathrm{t}-1$ is the error correction term, and $\beta 1$ is the correction factor.) 


\section{EMPIRICAL ANALYSIS}

\section{A. Causality test}

\section{1) Indicator selection and data description}

This paper examines the cause and effect relationship between tourism and economic growth in Shaanxi province from the market economy. Therefore, when we choose the index, we use the tourism revenue of 2005-2015 years in Shaanxi province TC (domestic tourism revenue TF and inbound tourism revenue TN) to represent the development of tourism, and the economic growth is expressed by the gross national product GDP

In order to exclude the effect of price changes, I used the GDP index (last year $=100$ ) to convert the regional GDP into real GDPs. The outbreak of SARS in the whole country in 2003 caused a strong impact on the tourism industry in Shaanxi Province, resulting in a large decline in tourism income. In order to eliminate its influence, interpolation method was adopted to amend, the specific methods are as follows:

$$
\mathrm{Yn}=\mathrm{Ya}+(\mathrm{n}-\mathrm{na}) \times \mathrm{d}(1)
$$

Where $d$ is the tolerance value for interpolating, $d=(Y b-$ Ya) / (nb - na)

$\mathrm{Yn}$ is the interpolated value, $\mathrm{Ya}$ is the starting point value, and $\mathrm{Yb}$ is the ending point value.

\section{2) Description analysis}

First of all, we should check the stability of the data to prevent the phenomenon of pseudo-regression. In order to linearize the data trend without affecting cointegration and eliminate the influence of heteroscedasticity, I take the natural logarithm of the data. The variables obtained by taking the natural logarithm of the data are described as LNGDPLNTC, the first order difference and the second order difference for the logarithmic data are denoted as DLNGDPDLNTCU D2LNGDPD2LNTC.The time series and the difference sequence diagrams of the two time series are plotted using Eviews as shown in Fig.1 and Fig.2:

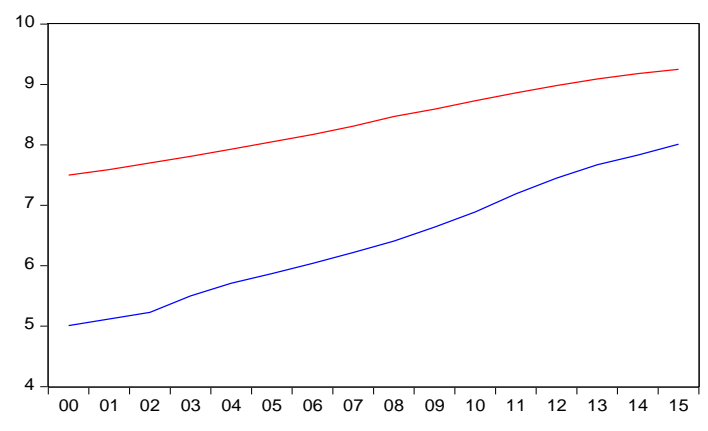

- LNTOUP — LNGDP

Fig. 1 TC and GDP timing diagram

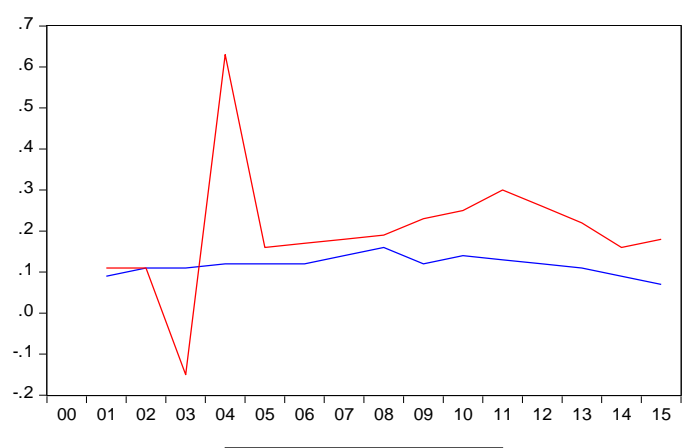

Fig. 2 First-order differential timing diagram

From Fig. 2, we can see that the GDP of TCU is on the rise, and all of them are non stationary time series. After the first order difference, the data fluctuate around a certain value over time.

\section{3) Stability test}

Further judgment is needed to determine whether the sequence is a stationary time series. In this paper, ADF unit root test is used to test the stationarity of time series. The results are shown in Table 1.

TABLE I ADF TEST RESULTS

\begin{tabular}{|c|c|c|c|}
\hline Variables & $\begin{array}{c}\text { Inspection type } \\
(\mathrm{C}, \mathrm{T}, \mathrm{K})\end{array}$ & ADF test statistics & Conclusion \\
\hline LnGDP & $(\mathrm{C}, \mathrm{T}, 3)$ & -0.834769 & Non-stationary \\
\hline DlnGDP & $(0,0,3)$ & -4.029304 & stationary \\
\hline LnTOUP & $(\mathrm{C}, \mathrm{T}, 3)$ & -3.556472 & Non-stationary \\
\hline DlnTOUP & $(0,0,2)$ & -7.537264 & stationary \\
\hline
\end{tabular}

As can be seen from Table 1, we can see that the GDP and lnTOUP in the 5\% significant level did not pass the ADF test, which is the non-stationary sequence. After the first order difference, both DlnGDP and DlnTOUP have passed the significant test of 5\%, so they reject the original hypothesis that $\operatorname{lnGDP}$ and $\operatorname{lnTOUP}$ are first-order monolithic sequences.
4) Cointegration analysis

Firstly, the OLS method is used to estimate the long-term linear equilibrium relationship between LnGDP and LnTOUP by cointegration regression of Ln GDP and LnTOUP. If the regression staggeredis stationary, then LnTOUP and Ln GDP are cointegrated, and there is a long-term stable "equilibrium" relationship between the two variables. 
First, the regression equation can be obtained by least $\mathrm{R} 2=0.993 \quad \mathrm{~F}=2064.318$ D.W $=0.423$ squares method:

$$
\mathrm{LnGDP}=4.605811+0.588744 * \operatorname{LnTOUP}
$$

TABLE II RESIDUAL ADF TEST RESULTS

\begin{tabular}{|c|c|c|c|}
\hline Variables & Inspection type & ADF test statistics & Conclusion \\
\hline$\varepsilon 1$ & $(0,0,3)$ & -3.417249 & stationary \\
\hline
\end{tabular}

From the regression results of model 1, it can be seen that the model with a fitting degree of 0.993.LnGDP and LnTOUP has a higher degree of fitness. The variables and equations have passed the significance test, and the residual error does not have a sequential correlation. From the result of unit root test of residual $\varepsilon 1$, it can be seen that the statistical quantity of $\mathrm{ADF}$ is less than the critical value at a significant level of 5\%, which indicates that the residual sequence is stable, and there is a cointegration relationship between tourism income and regional GDP in Shaanxi Province.

\section{5) Error correction model}

Cointegration reflects the long-term equilibrium relationship between tourism income and economic growth in Shaanxi Province. Therefore, based on the co-integration relationship, the error correction model is established as follows:

$$
\text { DLnGDP=0.470302*DLnTOUP-0.669311ECM (-1) }
$$

All the explanatory variables in the error correction model have passed the significance test that the D.W statistic is 1.66 , and the coefficient of error correction is -0.669311 , that is, the error correction term will pull the disequilibrium state back to the long-term equilibrium state with the force of 0.67 adjustment.

\section{6) Granger causality test}

The above test results show that there is a long-term equilibrium relationship between tourism revenue and growth in Shaanxi Province, but whether this relationship constitutes a causal relationship still requires further analysis using the Granger causality test. The optimal lag order determined by the AIC criterion is 3 . The results are given in Table 3:

\begin{tabular}{|c|c|c|c|c|c|}
\hline $\begin{array}{l}\text { Lag } \\
\text { order }\end{array}$ & Zero hypothesis & $\mathrm{F}$ & $\mathrm{P}$ & $\begin{array}{l}\text { Observation } \\
\mathrm{s}\end{array}$ & $\begin{array}{l}\text { Conclusio } \\
\mathrm{n}\end{array}$ \\
\hline \multirow{2}{*}{3} & LnGDP is not Granger Cause of LnTOUP & $\begin{array}{l}11.297 \\
3\end{array}$ & $\begin{array}{l}0.00 \\
70\end{array}$ & \multirow{2}{*}{13} & Refuse \\
\hline & LnTOUP is not a Granger cause of LnGDP & $\begin{array}{l}0.1089 \\
4\end{array}$ & $\begin{array}{l}0.95 \\
18\end{array}$ & & Accept \\
\hline
\end{tabular}

TABLE III GRANGER CAUSALITY TEST OF LNGDP AND LNTOUP

From the Granger causality test of LnGDP and LnTOUP, we can see that LnTOUP is not the Granger cause of LnGDP at the 5\% significance level, and LnGDP is the Granger cause of LnTOUP. This shows that economic growth can promote the development of tourism to a certain extent, but tourism cannot promote economic growth.

\section{CONCLUSION}

\section{A. The nature of the Silk Road Economic Belt.}

The construction of "Belt and Road" needs information construction, which is an important engine to drive the development of economy in the countries concerned with "Belt and Road". The essence of the Silk Road Economic Belt is to promote the exchange and communication of information between countries and regions, and to solve the problem of information asymmetry, so the New Silk Road also became the Information Silk Road. Through the construction of "Belt and Road", countries along the route are connected to each other in information exchange, and make great efforts to realize policy communication, facilities communication, trade communication, fund financing, and mutual understanding among the people.
B. The Motive Force of Tourism Driving Economic Growth under the Construction of Silk Road Economic Belt.

According to the theory of market economy, the market economy is the premise of equality, the full development of competition, and the social condition for the legal system to play a social role. The reason for economic growth is the improvement of market efficiency. Under the background of economic globalization, open market makes information sharing and information symmetry, thus improving market efficiency and optimizing resource allocation.

Local tourism can only stimulate domestic demand, can not promote the efficiency of regional resource allocation, give play to the advantages of market economy, so it is urgent to promote the development of cross-border tourism. The construction of Silk Road Economic Belt provides an opportunity for the development of cross-border tourism. Culture is the soul of the Silk Road tourism. As the oriental starting point of the Silk Road, Shaanxi has a long history of culture that will attract more domestic and foreign tourists. Cross-border tourism as a bridge of information communication will promote cultural communication and exchange between Shaanxi and the world. The development of 
tourism not only promotes the prosperity of regional economy, but also promotes the development of top-bottom economy by means of chain effect, industrial effect and linkage effect. Thus, the stable growth of regional economy and the exchange of information make investment and trade possible, thus promoting the development of local economy.

\section{Central Content of Tourism Development in the}

Construction of Silk Road Economic Belt

Shaanxi, as the starting point of the Silk Road, faces Central Asia, European Economic area, backed by the vast economic hinterland of east and central China, and plays an important role of "economic bridgehead" in the process of westward development of Chinaundefineds economy. In promoting the development strategy of the "Silk Road Economic Belt", the inherent advantages and international influence of the Silk Road tourism resources enable the tourism industry to stand out and take the lead in becoming the leading industry of the "Silk Road" economic belt. Giving full play to the guiding and demonstrating role of tourism provides an important opportunity for the development of Shaanxi tourism and the development of economy.

\section{REFERENCES}

[1] Archer B. Tourism in Mauritius:An economic impact study with marketing implications [J].Tourism Management, 1985, 6(1):50-54.

[2] DRISAKIS N. Tourism as a long-run economic growth factor:An empirical investigation for Greece using a causality analysis [J]. Tourism Economics, 2004, 10:305-316.

[3] Jacint Balaguer,Manuel Cantavella-Jorda. Tourism as a long-run economic growth factor: the Spanish case [J]. Applied Economics,2002,34(7):877-884.

[4] Qu Hua, Xia Jie Chang. An empirical study on the relationship between Tourism Development and Economic growth in China-based on data from 1985 to 2009 [J]. Finance and Trade economy, 2011( 8): 106-112.

[5] Li Qiuyu, Huang Yue, et al. Spatial situation of the relationship between Tourism dependence and Economic growth in Guangdong Province [J]. Economic Geography, 2015, 35 (5): 185-191. 